\title{
Two categorial issues of degree constructions in Mandarin
}

\author{
Niina Ning Zhang ${ }^{1}$
}

Received: 12 February 2021 / Accepted: 29 June 2021 / Published online: 21 September 2021

(C) The Author(s) 2021

\begin{abstract}
This squib argues against Yiwen Zhang's (J East Asian Linguist 29:393-434, 2020) adjective analysis of the Mandarin word you 'have' to the left of a gradable noun, as in you yongqi 'have courage', showing that it is a verbal element. It also shows that for a gradable predicate of any category, if the question under discussion is about a comparison of individuals with respect to a gradable property, the degree word hen 'very' is banned; if the question under discussion is about the content of a gradable property of an individual, hen must occur; and finally, if the question under discussion is not about either of the two above, hen is optional.
\end{abstract}

Keywords Gradable noun · Category · Degree word · Question under discussion · Mandarin
Abbreviations
BA Causee
CL Classifier
MOD Modification
PRF Perfective aspect
PRT Sentence-final particle
Q Question
RED Reduplicant

Niina Ning Zhang

Lngnz@ccu.edu.tw

1 Graduate Institute of Linguistics, National Chung Cheng University, 168 University Rd., MinHsiung, Chia-Yi 62102, Taiwan 


\section{Introduction}

In Mandarin, gradable predicates can be of various syntactic categories. In (1a), yonggan 'brave' is an adjective; and in (1b), yongqi 'courage, braveness', which follows you 'have', is a noun.

(1) a. Awen hen yonggan. b. Awen hen you yongqi. Awen very brave Awen very have courage 'Awen is brave.' 'Awen is brave.'

In some other languages, gradable predicates can also be of various syntactic categories, as seen in the adjective in (2a) and the noun in (2b) (Francez \& KoontzGarboden 2017: 1).

(2) a. Krishna is wise b. Krishna has wisdom

This squib first challenges Zhang's (2020: §4.2) claim that a phrase that contains you 'have' and a gradable NP, as in (1b), is an Adjective Phrase. I call this use of you Pre-Gradable Noun you (PGN-you hence). Second, it challenges the popular belief that the degree word hen 'very' is not obligatory when the non-comparative predicate is a VP in Mandarin, such as xihuan Lisi 'like Lisi' (e.g., Grano 2012: 536, 558). The goal of this squib is not to argue for or against a particular view, but rather to clarify certain empirical issues regarding the syntactic properties of PGN-you and the interactions between various types of gradable predicates and the presence of hen, and to motivate generalizations which any adequate theory must account for.

In Sect. 2, I argue that PGN-you is a verbal element. In Sect. 3, I demonstrate the crosscategorial patterns of the presence of hen with gradable predicates. Sect. 4 is a conclusion.

\section{You 'have' as a verb in gradable NP constructions}

In this section, I argue for the verbal category of PGN-you. PGN-you is not a substantial word, since it has no obvious semantic role other than to support a gradable nominal to function as a predicate. Thus, the AP construction in (1a) and the NP construction in (1b) are truth-conditionally identical (also see Francez \& KoontzGarboden 2015, 2017 for the semantics of the examples in (2) and their counterparts in other languages). If PGN-you does not occur, a gradable NP can neither be a predicate, as seen in (3a), nor be selected by a degree word, as seen in (3b) (cf. (1b)).

a. Awen *(you) yongqi ma?
Awen have courage Q
'Is Awen brave?'

b. Awen hen *(you) yongqi.

Awen very have courage 'Awen is brave.'

Zhang (2020: 425) tries a semantic approach to the category of PGN-you. Since the combination of PGN-you and an NP is truth-conditionally equivalent to its correlated AP, she claims that the combination is also an AP. However, syntactic 
category can only be identified by morpho-syntactic evidence. If semantics could decide the category of the you+NP string, where you plays no semantic role, the string would be an NP, instead of the alleged AP.

The category of a phrase is determined by the head of the phrase. Zhang admits that PGN-you and the gradable NP are sisters (p. 431). If their mother node is not $\mathrm{NP}$, the category of the mother must be decided by PGN-you. If Zhang claims that the phrase is an AP, she assumes that this you is an adjective. I falsify this assumption and argue that this you is a verb, with four arguments: negation, control, reduplication, and stranding.

First, all verbs allow mei 'not', whereas all adjectives allow bu 'not', in their negative forms. For example, the verb chouyan 'smoke' can occur with mei in (4a), and the adjective gao 'tall' can occur with $b u$ in (4b). PGN-you allows mei, but rejects $b u$, as seen in (5).

(4) a. Awen $\{\mathrm{mei} / \mathrm{bu}\}$ chouyan. b. Awen not/not smoke Awen does not smoke.'

b. Awen $\{*$ mei/bu $\}$ gao. Awen not/not tall 'Awen is not tall.'

(5) Wo renwei Awen $\{\mathrm{mei} / * \mathrm{bu}\}$ you zhihui. I think Awen not/not have wisdom 'I think Awen is not smart.'

If PGN-you is a verb, the acceptability of the mei-version in (5) is expected (cf. (4a)). If PGN-you were an adjective, it would allow $b u$, as in the adjective construction in (4b), contrary to the fact. Thus, the adjective analysis of PGN-you makes a wrong prediction.

Second, only verbs can control the dependent subject of an embedded clause, whereas no adjective can do so. A clause introduced by the complementizer lai 'come' is a purposive clause that has a PRO subject (Liao \& Lin 2019), as seen in (6a). An adjective can never control a lai-clause. As seen in (6b), yonggan 'brave' cannot control the lai-clause. Like the verb in (6a) and unlike any adjective, PGNyou can control the dependent subject of a lai-clause, as seen in (6c).
a. Ta mai-le yi
he buy-PRF one
zhang caipiao
[lai
shi 'He bought a lottery ticket to try his luck.'
b. Ni yonggan (*lai shi yixia) ma?
you brave to
try once
Q
'Are you brave?'
c. Ni you yongqi [lai shi yixia] ma?
you have courage to try once Q
'Are you brave enough to have a try?'

yixia shouqi].

It needs to be clarified that in (6c), the lai-clause does not form a complex nominal with yongqi 'courage', since the cluster yongqi lai shi yixia does not behave like a nominal. (7a) shows that the cluster cannot function as subject, unlike zhe jian 
$s h i$ 'this matter'; and (7b) shows that it cannot follow a possessor, unlike the noun yongqi 'courage'.

(7) a. Wo renwei \{zhe jian shi/ *yongqi lai shi yixia\} hen zhongyao. I think this CL matter courage to try once very important 'I think this matter very important.'

b. Wo peifu tade \{yongqi/*yongqi lai shi yixia\}. I admire his courage/courage to try once 'I admire his courage.'

Verbs such as xihuan 'like', and, as pointed out by an anonymous reviewer, some other stative verbs such as tang 'lie' and verbs with the imperfective aspect marker $z a i$, do not control an embedded subject in a lai-clause. But these constraints do not affect the categorial contrast that no adjective but some verbs can do so. Since PGNyou can do so, it is not an adjective.

Third, adjectives and verbs have different reduplication patterns in Mandarin, as recognized by Zhang (2020: 424). However, Zhang does not consider a reduplication test, because she wants to identify the category of the whole [you $+\mathrm{NP}]$ phrase, rather than that of PGN-you (p. 424). As we stated above, only when the category of PGN-you is identified, can the category of its combination with an NP be decided. Since PGN-you itself is not a phrase, reduplication can be used to check its category.

For a monosyllabic adjective, its reduplication form is XX-de. In (8a) (see Liu 2010: 1012), the reduplicate adjective occurs as a predicate; and in (8b), it occurs as an attributive.

(8) a. Awen gaogao-de. b. Wo kanjian-le na ge gaogao-de nanhai. Awen tall.RED-DE I see-PRF that CL $\overline{\text { tall.RED-DE }}$ boy 'Awen is tall.' 'I saw that tall boy.'

But no monosyllabic verb can appear in an XX-de form, as seen in (9a). Like a verb and unlike an adjective, the monosyllabic PGN-you never appears in such a form, as seen in (9b). ${ }^{1}$
*Awen ai-ai-de
hua.
b. *Awen you-you-de yongqi.
Awen love-RED-DE flower
Awen have-RED-DE courage

Also, Zhang's adjectival analysis of the cluster you $\mathrm{N}$ wrongly predicts that the cluster should behave like an adjective if it were reduplicated. In (10a), the adjective is reduplicated in an AABB-de form; and (10b) shows that the you $\mathrm{N}$ cluster cannot

\footnotetext{
${ }_{1}^{1}$ Functional elements, as well as lexical ones, can be reduplicated, e.g., the quantifier mei 'each', the focus markers pian 'only', jin 'only', and $d u$ 'only', and all classifiers (N. Zhang 2014) can be reduplicated.
} 
be in this form. In (11a), the adjective is reduplicated in an ABAB-de form; (11b) shows that the you $\mathrm{N}$ cluster cannot be in this form. If the cluster were adjectival, it would follow the adjectival pattern of reduplication, contrary to the fact. Thus, neither PGN-you nor the you $\mathrm{N}$ cluster behaves like an adjective.
(10) a. gaoxing $=>$ gaogao-xingxing-de glad
b. you qian $=>$ *youyou-qianqian-de have money
(11) a. xue-bai $=>$ xuebai-xuebai-de snow-white
b. you qian $=>$ *youqian-youqian-de have money

Fourth, in Mandarin, if a functional or lexical verbal element has a complement, it can be stranded, as seen in (12); in contrast, an adjective has no complement to its right. Zhang (2020: 426) assumes that PGN-you might behave like the derivational suffix - ful in English, "which combines with a nominal and renders an adjective, such as beauty $\rightarrow$ beautiful". However, like the verbal elements in (12), PGN-you can be stranded, as seen in (13). This shows that PGN-you is a verbal element, taking the noun as its complement.

(12) a. Putao, Awen xihuan, lizhi, ta ye xihuan. grape Awen like litchi he also like Grapes, Awen likes, and litchis, he also likes.'

b. Awen hui lai, Ali ye hui. Awen will come Ali also will 'Awen will come, and so will Ali.'

(13) a. Zhihui, Awen you. Yongqi, ta ye you. wisdom Awen have courage he also have 'Wisdom, Awen has, and courage, he also has.'
b. Awen you caihua, Lili ye you. Awen have talent Lili also have
'Awen has talent, and so does Lili.'

It needs to be pointed out that the strandability of PGN-you supports Zhang's claim that the PGN-you cluster is a phrase, not a complex word that is composed of an affix and a noun.

Based on the above four arguments, I conclude that PGN-you is a verbal element. Nevertheless, I call the predicate supported by PGN-you gradable NP predicate, to distinguish it from the predicate headed by a substantial verb such as xihuan 'like'.

One anonymous reviewer asked whether the word you has different flavors and whether in this particular flavor, i.e., PGN-you, it is an adjective, rather than a verb, which is seen in other constructions such as a possessive one. It is true that $\mathrm{v}$ has been claimed to have "different semantic flavors" (Arad 2005: 197; also see Folli \& Harley 2007), which correlate with different argument structures. However, the semantic variation is within the same verbal category. If an element can be used as either an adjective or a verb, it shows systematic syntactic contrasts in the two uses. 
What we have seen is that PGN-you simply does not show any adjective properties. Moreover, Koontz-Garboden (2016) and Koontz-Garboden and Francez's (2010) diachronic and typological research shows that one and the same HAVE-morpheme is used in possessive and property concept constructions in many languages.

\section{The presence of hen 'very' with gradable predicates of various categories}

\subsection{A categorial contrast?}

There seems to be a haunting question in Mandarin: in non-comparative readings, why is it the case that "degree expressions are not obligatory when the predicate is verbal" (Grano 2012: 535; also see Zhang 2020: 422), as seen in (14c), but obligatory when the gradable predicate is adjectival, as seen in (14a), and nominal, as seen in $(14 b) ?^{2}$

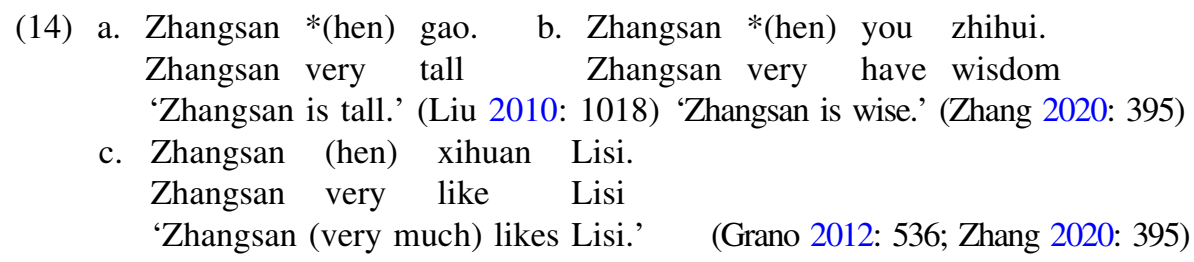

The contrast between gradable APs and VPs has been well-assumed and extensively discussed in works such as Grano (2012), and the parallel contrast between gradable NPs and gradable VPs is discussed in Zhang (2020). However, the acceptability pattern assumed in this haunting question is not accurate. We show that the distribution of hen is sensitive to the context. Following the Gricean maxim of relevance, interlocutors deliver the utterance meaning that is intended to address the question under discussion (QUD) (Roberts 2012; Koev 2018). In fact, in all three (i.e., AP, NP, VP) constructions, the following three generalizations hold in Mandarin.

\footnotetext{
${ }^{2}$ In this paper, we discuss hen 'very' only, not other degree words. In some constructions, the degree word cannot be replaced with hen, as seen in (i). We do not discuss this issue here. Also, hen and adjective reduplication, as seen in (8), are in complementary distribution (Zhang 2015). We do not consider reduplication in this section.
}

(i) Awen xian [wo $\{$ tai/*hen $\}$ ben $]$.

Awen dislike I too/very fool

'Awen dislikes me, thinking me too foolish.' 
(15) a. If the QUD is to provide the content of a gradable property, hen must occur.

b. If the QUD is about a comparison between individuals with respect to a gradable property, hen does not occur.

c. If the QUD is not about either of the above two, hen can be optional.

(15a) addresses the issue WHAT $\mathrm{P}(\mathrm{P}=$ property) $\mathrm{X}$ has; (15b) addresses the issue WHICH ONE has more P; and (15c) does not address either of the two issues. (15a) and (15b) are based on works such as Sybesma (1999: 26-27), Liu (2010), and Grano (2012: 516) for AP constructions, and Zhang (2020: 395) for NP constructions. We show the cross-categorial nature of these three generalizations in the following subsections. Note that in this section, examples with $*$ are unacceptable only in the given context.

\subsection{QUD A: a gradable property}

Context: No comparison between individuals is available; instead, the speaker provides the content of a gradable property. For example, the question in (16a) can be answered in the AP construction in (16b), or the NP construction in (16c), or the VP construction in (16d). In this context, hen is obligatory in the answers. (15a) is thus confirmed.
a. Awen dui zhe jian shi de taidu zenmeyang? Awen to this $\mathrm{CL}$ issue MOD attitude how
'How does Awen react to this issue?
b. Ta*(hen) keqi. AP c. Ta *(hen) you limao.
he very polite he very have politeness
'He is polite.' 'He is polite.'
d. Ta *(hen) danxin zhe jian shi. VP
he very care this $\mathrm{CL}$ matter
'He is worried about the matter.'

(15a) is also seen in complememt clauses. If a person asks about the characteristics of an individual, without a comparison with anyone else, the following are possible answers. In addition to faxian 'discover', tingshuo 'hear' can also be the matrix verb in these constructions. 
(17) a. Women faxian [ta *(hen) congming]. (Grano 2012: 551) we discover he very smart

'We discovered he's smart.'

b. Women faxian [ta *(hen) you caihua]. we discover he very have talent

'We discovered he's talented.'

c. Women faxian [ta *(hen) danxin zhe jian shi]. VP we discover he very care this $\mathrm{CL}$ matter 'We discovered he's worried about the matter.'

(15a) is also seen in the modifiers of nominal predicates. If one talks about a letter and asks what kind of a letter it is, the following are possible answers. Hen is required in all of them.

a. Na shi yi feng *(hen) chang de
that be one CL very long DE
'That is a long letter.'
b. Na shi yi feng *(hen) you shuiping de

If an expression directly provides the answer to the question that asks about the property of an individual, the expression follows QUD A, regardless whether the expression is the matrix or embedded predicate. For such an expression, hen is obligatory.

\subsection{QUD B: comparison between individuals}

Context: A comparison of individuals occurs. To answer the questions in the a-forms in (19) through (22), hen is rejected, as seen in the answers in the correlated 
b-forms. (19b) is an AP construction, (20b) is an NP construction, and (21) and (22) are VP constructions.

(19) a. Lili gen Awen, shei bijiao keqi?

Lili and Awen who comparatively polite

'Who is politer between Lili and Awen?'

b. Awen (*hen) keqi. ${ }^{3}$

Awen very polite

'Awen is politer.'

(20)
a. Lili gen Awen, shei
bijiao
you limao?
Lili and Awen who
comparatively have politeness

'Who is politer between Lili and Awen?'

b. Awen (*hen) you limao.

Awen very have politeness

'Awen is politer.'

(21)
a. Lili gen Awen, shei
bijiao
xihuan manhua?
Lili and Awen who
comparatively like
comics

'Between Lili and Awen, who likes comics more?'

b. Awen (*hen) xihuan manhua.

Awen very like comics

'Awen likes comics more.'

3 (19a) can also be answered by (i) or (ii), where hen occurs, without comparing the two persons, as expected.

(i) Awen gen Lili dou hen keqi. (ii) Awen hen keqi, Lili ye hen keqi. Awen and Lili all very polite Awen very polite Lili also very polite 'Awen and Lili are both polite.' 'Awen is polite, and Lili is also polite.'

(19a) can also be answered by (iii), a conjoined comparative (Rett 2020: 168). Also, the examples in (13) can be conjoined equatives (Rett 2020). We do not consider this strategy in this paper (cf. Liu 2010: 1027).

(iii) Awen hen keqi, dan Lili bu name keqi.

Awen very polite but Lili not that polite

'Awen is polite, but Lili is not that polite.' 
(22)
a. Lili gen Awen, ni
xihuan
nayige?
Lili and
Awen you
like
which

'Between Lili and Awen, which one do you like more?'
b. Wo (*hen) xihuan Awen.
I very like Awen
'I like Awen more.'

$\mathrm{VP}$

In all of these dialogues, a comparison of individuals occurs: either the individual denoted by the subject, as in the first three dialogues, or the individual denoted by the object, as in the last one, is compared with another individual. These answers can also be preceded by wo juede 'I think', functioning as embedded clauses. Hen is banned in the answers consistently.

In addition to the overt individuals given in the questions, the individuals to be compared can also be salient individuals in the context (I thank an anonymous reviewer for asking me to address this). Imagine that one needs to choose a taxi or a subway to go to a place as soon as possible. When he realizes that the former is faster, he can say (23), where hen is rejected.

(23) (Wo juede) jichengche (*hen) kuai.

I think taxi very fast

'(I think) a taxi is faster.'

Thus, if the QUD is a comparison of individuals, hen is banned systematically. (15b) is confirmed. (15b) is expected, since a comparative predicate rejects hen (e.g., L. Zhang 2019):

(24) Awen bi Lili (*hen) keqi.

Awen than Lili very polite

'Awen is politer than Lili.'

\subsection{QUD C: neither QUD A nor QUD B}

Context: If the QUD is not about either the content of a gradable property or a comparison of individuals, hen can be optional. For instance, a polar question that contains a gradable expression can, but does not have to, have hen, as seen in (25a). This is also true of its answer, as seen in (25b). In this context, the speaker wants to confirm the existence or absence of a certain gradable property of an individual, rather than provide the content of any property or compare different individuals with respect to any property. When hen occurs and bears a stress, it functions as an intensifier. This can be seen in the elaborated answer in (25c). The same optionality is true of NP and VP constructions, as seen in (26) and (27), respectively. 
(25)
a. Awen (hen) yonggan ma?
b. Ta (hen) yonggan. ${ }^{4}$ AP

Awen very brave Q

he very brave

'Is Awen very brave?'

'He is (very) brave.'

c. Ta hai suan yonggan ba, buguo shuo-bu-shang hen yonggan.

he yet count brave PRT but say-not-up very brave

'He can be counted as brave, but is not yet up to very brave.'

(26)

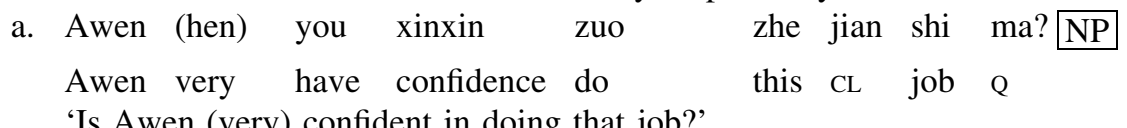

'Is Awen (very) confident in doing that job?'

$\begin{array}{lllllll}\text { b. Ta queshi (hen) you } & \text { xinxin } & \text { zuo zhe jian shi. } \\ \text { he indeed very have } & \text { confidence do this CL job }\end{array}$

'He is indeed (very) confident in doing this job.'
a. Awen (hen) xihuan Lili ma?
b. Ta (hen) xihuan Lili. VP
Awen very like Lili Q
he very like Lili
'Does Awen like Lili (very much)?'
'He likes Lili (very much).'

See Liu (2010: 1019, 1046) for more gradable AP examples like those in $(25 a, b)$, and Zhang (2020: 427-428) for more gradable NP examples like those in (26).

QUD C is also seen in other contexts. The conditional clauses in (28) and the noun-modifiers in (29) are neither intended to compare any individuals, nor to answer any what $\mathrm{P}$ question. The QUD of the examples is addressed by the matrix predication. For example, the QUD of (28a) is addressed by the predicate headed by gua 'hang', rather than by a comparison between the coat denoted by the subject of the conditional and another coat with respect to the degree of wetness. The QUD of (29a) is also addressed by the matrix predicate, headed by gua, rather than by a comparison between the coat denoted by the modifiee of chaoshi 'wet' and another coat with respect to the degree of wetness. In these constructions, hen occurs if the embedded gradable predicate is emphasized. In all of these gradable predicates, hen can be optional. (15c) is thus confirmed.

(28) a. [Ruguo dayi (hen) chaoshi], jiu ba ta gua zai shu-shang. AP if coat very wet then BA it hang at tree-on

'If the coat is (very) wet, hang it up on the tree.'

b. [Ruguo ta (hen) you nengli], ni jiu bie dangxin la. NP if he very have ability you then not worry PRT

'If he is (very) diligent, you should not be worried.

c. [Ruguo ta (hen) xihuan Lili], ni jiu bie dangxin la. VP if he very like Lili you then not worry PRT

'If he likes Lili (very much), you should not be worried.'

\footnotetext{
$\overline{4}$ The dialogue in (25a)-(25b) is similar to Grano's (2012: 541 (91)-(92)), who credited one of his anonymous reviewers with the observation that direct responses to polar questions do not require the occurrence of hen.
} 
(29) a. Awen ba na jian [(hen) chaoshi] de dayi gua zai shu-shang. AP Awen BA that CL very wet MOD coat hangat tree-on 'Awen hung up that (very) wet coat on the tree.'

b. Awen jiang-le yi ju [(hen) you zheli] de hua. NP Awen say-PRF one CL very have philosophy MOD sentence 'Awen said a sentence that is (very) philosophical.'

c. Awen mai-le yi kuai [ta (hen) xihuan] de dangao. VP Awen buy-PRF one piece he very like MOD cake 'Awen bought a piece of cake that he likes (very much).'

This QUD analysis applies to other constructions in which the absence of hen does not have to trigger a comparison reading (see Liu 2010 for such constructions).

Eventually, there is no contrast between gradable predicates of different syntactic categories, with respect to the presence of hen (contra Grano 2012 and Zhang 2020). We have thus achieved unified generalizations, seen in (15), from the perspective of QUD.

\section{Conclusions}

First, PGN-you is a verbal element, and thus it heads a VP, rather than an AP. Second, cross-categorially, the presence and absence of hen correlate with the QUD of the construction: if the QUD is about a comparison of individuals with respect to a gradable property, hen is banned; if the QUD is about the content of a gradable property of an individual, hen must occur; and finally, if the QUD is not about either of the above two, hen is optional.

Acknowledgments I am grateful to the three anonymous reviewers and the editors of the journal for their very helpful comments. Remaining errors are mine. This work was supported by the grant MOST1082410-H-194-019-MY3 from the Ministry of Science and Technology, Taiwan.

Open Access This article is licensed under a Creative Commons Attribution 4.0 International License, which permits use, sharing, adaptation, distribution and reproduction in any medium or format, as long as you give appropriate credit to the original author(s) and the source, provide a link to the Creative Commons licence, and indicate if changes were made. The images or other third party material in this article are included in the article's Creative Commons licence, unless indicated otherwise in a credit line to the material. If material is not included in the article's Creative Commons licence and your intended use is not permitted by statutory regulation or exceeds the permitted use, you will need to obtain permission directly from the copyright holder. To view a copy of this licence, visit http:// creativecommons.org/licenses/by/4.0/.

\section{References}

Arad, Maya. 2005. Roots and patterns: Hebrew morpho-syntax. Dordrecht: Springer. 
Folli, Raffaella, and Heidi Harley. 2007. Causation, obligation, and argument structure: On the nature of little v. Linguistic Inquiry 38 (2): 197-238.

Francez, Itamar, and Andrew Koontz-Garboden. 2015. Semantic variation and the grammar of property concepts. Language 91 (3): 533-563.

Francez, Itamar, and Andrew Koontz-Garboden. 2017. Semantics and morphosyntactic variation: Qualities and the grammar of property concepts. Oxford: Oxford University Press.

Grano, Thomas. 2012. Mandarin hen and Universal Markedness in gradable adjectives. Natural Language and Linguistics Theory 30: 513-565.

Koev, Todor. 2018. Notions of at-issueness. Language and Linguistics Compass 12 (12): e12306.

Koontz-Garboden, Andrew. 2016. Thoughts on diagnosing morphomicity: A case study from Ulwa. In The Morphome Debate: Diagnosing and Analysing Morphomic Patterns, ed. Ana Luís and Ricardo Bermúdez-Otero, 89-111. Oxford: Oxford University Press.

Koontz-Garboden, Andrew, and Itamar Francez. 2010. Possessed properties in Ulwa. Natural Language Semantics 18 (2): 197-240.

Liao, Wei-wen Roger., and Tzong-hong Jonah. Lin. 2019. Syntactic structures of Mandarin purposives. Linguistics 57 (1): 87-126.

Liu, Chen-Sheng. 2010. The positive morpheme in Chinese and the adjectival structure. Lingua 120 (4): 1010-1056.

Rett, Jessica. 2020. Separate but equal: a typology of equative constructions. In Interactions of Degree and Quantification, edited by Peter Hallman. Leiden: Brill, 163-204.

Roberts, Craige. 2012. Information structure in discourse: Towards an integrated formal theory of pragmatics. Semantics and Pragmatics 5: 1-69.

Sybesma, Rint. 1999. The Mandarin VP. Dordrecht: Kluwer Academic Publishers.

Zhang, Linmin. 2019. The semantics of comparisons in Mandarin Chinese. In Sae-Youn Cho (ed.), Proceedings of GLOW in Asia XII \& SICOGG XXI, 616-625.

Zhang, Niina Ning. 2014. Expressing number productively in mandarin Chinese. Linguistics 52 (1): 1-34.

Zhang, Niina Ning. 2015. Functional head properties of the degree word hen in mandarin Chinese. Lingua 153: $14-41$.

Zhang, Yiwen. 2020. Nominal property concepts and substance possession in Mandarin Chinese. Journal of East Asian Linguistics 29 (4): 393-434.

Publisher's Note Springer Nature remains neutral with regard to jurisdictional claims in published maps and institutional affiliations. 